\author{
Crossing the Border: International Journal of Interdisciplinary Studies \\ Volume 3; Number 1; 15 January 2015 \\ ISSN 2350-8752 (Print); ISSN 2350-8922 (Online)
}

\title{
KARL POLAYNI, MARKET ECONOMY AND ECONOMIC LIBER- ALISATION IN NEPAL
}

Krishna P. Pandey (Nepal)

\begin{abstract}
This review essay is a short account for Karl Polanyis alternative interpretation of the world economic history that largely relies on the comparative analysis of two forms of economic exchanges; non-market and market. The replacement of reciprocity and redistribution produced by the market economy based on the principles of profit making, gain and competition, in which money has a central role, is the key argument that Polanyi brings into consideration. His notion of market economy that is self-regulating by its very nature has been synonymous with the free market practice under economic liberalization policy adopted by the capitalist societies nowadays. Despite his projection of the collapse of the market economy in the future, it is gaining ground along with frequent adjustments, adaptations and compromises with other dynamics of society, which could be considered as a new form of embeddedness. The essay raises few analytical issues embeddedness from Nepal's exercise of market economy on the backdrop of Polanyis notion of self-regulating market.
\end{abstract}

KEYWORDS: Market economy, non-market economy, economic liberalisation, selfregulating market, embeddedness

\section{INTRODUCTION}

Amidst the devastating effect of the Second World War on both social and economic orders of the world, Karl Polanyi came up with a seminal book The Great Transformation in 1944, which introduced the substantive interpretation of economic system by largely revisiting the very assumptions of neo-classical economics. Primarily, the book turned to be a cornerstone in terms of unearthing the role of the institutions in shaping economic and market relations by reconnecting the market with larger socio-political dynamics through the notion of embeddedness. He is also noted for his comparative analysis of past and present economies with substantial emphasis on the key principles of reciprocity, redistribution and householding.

The book came as a challenge to the traditional economic thoughts largely rooted on Adam Smith, David Ricardo and Robert Malthus. Polanyi argued that economic system is inalienably embedded in society and culture. For him, market comes to be a crux of analysis since it has existed either in pre-capitalist society or in capitalist society. Only difference is the role it has played in these two forms of societies. Further clarity can be added with the statement that "[m]any pre-capitalist economies had marketplaces, but they did not have self-regulating, supply-and-demand market economies" (Isaac, 2005, p. 14).

Heavily influenced from Malinowski's work on Trobriand Islanders and, then, mi- 


\section{Crossing the Border: International Journal of Interdisciplinary Studies}

nutely analysing of their economic systems, he came to know that how an economic system efficiently functions even without the absence of self-regulating market. The success behind such an exchange economy, which had worked as a part of larger social and cultural system was rooted on the principles of reciprocity and redistribution, and the goal was meeting communal needs rather than accumulation and profit making. Polanyi's three forms of economic integration; namely reciprocity, redistribution and market exchange, characterise two different types of societies; the first two correlate with tribal or pre-industrial societies and the third with capitalist or market societies (Fusfeld, 1988). People in pre-market societies practised various types of reciprocal transactions merely to maintain social order by continuing and strengthening of kinship, friendship and other social ties in which economic activity was embedded. Industrial revolution brought substantial changes in the pre-industrial social order by separating market mechanism from social relations (Polanyi, 2001 [1944]). Subsequently, market came to be accepted as central to society (Hart and Hann, 2009) and started shaping all other social relationships.

\section{POLANYI AND THE ECONOMIC SYSTEM}

For the first time, according to Polanyi, Britain experienced the emergence of market economy during 1830s and it was expanded outside Britain along with the development of science and technology; he writes "[i]n 1834 industrial capitalism was ready to be started” (Polanyi, 2001 [1944], p. 106). It was further expanded almost all over the world through the colonial expansion including most of the contemporary third world countries, either they be colonised or never colonised. Thus, traditional economies were substituted and market became the ubiquitous and invincible entity having control over all aspects of social and cultural life.

For him, embeddedness is the fundamental characteristics of the pre-capitalist economies in which people used to practise various types of reciprocal transactions merely to maintain social order by continuing and strengthening of kinship, friendship and other social ties in which economic activity was embedded. The embeddedness of pre-market economies is characterised by two elements: reciprocity and redistribution. But Market economy is independent, dis-embedded from social relations, "controlled, regulated, and directed by market prices; order in the production and distribution of goods is entrusted to this self-regulating mechanism" (Polanyi, 2001 [1944], p. 71).

The dis-embedded market he is arguing is not the pre-industrial market which was only incidental to economic life; but is a self-regulating capitalist market, which is ruling the social and cultural life. Self regulation, for Polanyi, is the "capacity of organising the whole of economic life without outside help or interference" (Polanyi, 2001 [1944], p. 45). The practicality of dis-embedded economy has also largely been questioned since truly free and self-regulating markets have been only myths till the date. Though he suggested us the notion of self-regulating market, also foresaw the counter-response expressed through protectionist measures to check the deficiencies of such markets. If the 'double movement' is expected to balance the sudden and unexpected disorders that self-regulating markets produce, the free market, first, comes to be embedded in the state and then in the society at large.

Polanyi wrote The Great Transformations before the limitations of self-regulating markets were clarified by the modern economists and when the international in- 
stitutions such as IMF, UN and World Bank were only in paper (Stigliz, 2001); and large part of the world was under colonial rule. Still, when he brought in the idea of 'double movement' to explain the state protection and control over the wide range of economic life, it seemed as if he was speaking directly to the contemporary difficulties of the third world economies. The double movement, which has been referred to challenge underlying logic of free market principles, has in essence two aspects (Maerthns, 2008, p. 130). The first is associated with the push for free market reforms by various groups in society where as the second refers to the counter movements that are "necessarily and spontaneously" mobilised against it (Maerthns, 2008, p. 130).

Market economy is independent, dis-embedded from social relations, "controlled, regulated, and directed by market prices; order in the production and distribution of goods is entrusted to this self-regulating mechanism" (Polanyi, 2001 [1944], p. 71 ). The problem with market economy is commodification of labour, land and money, which are not commodities or cannot be commoditised in real sense. By commoditizing land, labour and money, whole of the humanity and nature was brought into the market for sales and purchase. Thus, it is free market in money that "entails buying and selling society itself" (Hart, 2009, p. 95). Polanyi contrasts with traditional economists' treatment to money as a commodity by arguing that it was "not a commodity, it was purchasing power; far from having utility itself ..." (Polanyi, 2001 [1944], p. 205). Thus market, labour and money have occupied central space in Polanyi's analysis of transformation of pre-capitalist economic to market dominated capitalist system brought by the industrial revolution in Europe.

Polanyis dichotomization of the economy into embedded and dis-embedded could be a useful framework to understand the historical changes in the economic system but, at the same time, seems insufficient to study the foreign aid dependency, and intervention of international financial institutions and national government on third world liberal economy. Can such intervention be a part of the double movement which is thought to be required to check the market disorder or is a means of just gaining control over the third world market such as in Nepal?

\section{MONEY AND SELF REGULATED MARKET IN NEPAL}

The entry of money into Nepal's economy is not a recent one since its history goes back to the period of Lichchhavi king Mandev in fifth century who introduced coins engraved with his name (Shrestha and Singh, 1972). The coin became the medium of exchange in the economic transaction with neighbouring territories of that time. Contrary to Polanyi's claim, the king had not introduced the notion of money for establishing status of individuals but for facilitating and promoting the economic transaction within and outside the state. Various historical studies in Nepal suggest that not only money but also land and labour have become the major elements in market exchange even before its entry into the liberal economy. Francis Hamilton in his classic book An Account of the Kingdom of Nepal published in 1819 has recorded the market transaction through money, which is an early instance of the existence of the modern of form of market system. The practice of such market in Nepal was neither an outcome of industrial revolution in Europe nor of any other socio-political movements in western world; rather it was spontaneous evolution caused by local historical factors and accompanied by the evolution of larger Nepalese society and culture. 


\section{Crossing the Border: International Journal of Interdisciplinary Studies}

According to Polanyi's claim the money in market economy destroys the reciprocal exchange, since once goods are exchanged for money, the parties engaged in the transaction need not to meet again (Karnik, 2008). This is the basic characteristics of money in modern sense. The Nepalese money even in the fifth century functioned not as an entity of reciprocal exchange but met the need of general purpose money leaving no responsibility of reciprocal exchange to the transactors. Since then, money has occupied central space in Nepalese economic transaction even if it has not turned to be an omnipotent entity of regulating the exchanges.

The origin of market economy into a fundamentally non-market society was a sudden eruption rather than planned and having gradual development for Polanyi (Hart and Hann, 2009; Karnik, 2008). But, the penetration of free market economy in Nepal was more or less planned and imposed by international financial organizations. IMF and World Bank in 1980s came up with structural adjustment policies (SAPs) for developing countries as a prerequisite of receiving development support. Nepal's protectionist policies adopted till then in the guise of an import substitution strategy resulted inefficiency and the unproductive use of resources making ground to adopt structural adjustment policies (Khanal, 2012). The weakness of the state centred policy created conducive environment to launch the structural adjustment policies. Eventually, the market controlled through the state's interventionist policies came under the control of similar policies of international financial institutions.

Simply, the rule of demand and supply governs the market mechanism by commoditising everything and producing everything only for sale. The intention of the SAP was to liberate market from the grip of the state and let it function independently under the very principles of self-regulating market. This effort resulted in reduced subsides in service sector and agriculture in particular leading to rapid escalation of price in these sectors in Nepal's case. As Nepal's market is still based on mercantile economy, the nature of self-regulating market under it fundamentally differs from the production based market. Furthermore, external factors come to be determinant in shaping the exchange mechanism. One can ask, why do the products from developing countries face several hurdles to enter into the world market on the cause of quality, quota and so on? How do national markets compel restructure themselves under the interventionist policies of global financial organizations? All these issues get us further intrigued while we initiate to understand the real nature of Polanyiss self-regulating and dis-embedded market of third world countries like Nepal.

Polanyi's concepts of "embeddedness" and "dis-embeddedness" are the questions of degree, not only of kind. That is, neither of the economies is totally dis-embedded from larger social network because, for a sociologist, economic relations are also parts of social relations and bases of social interaction. The state centred development strategies before 1980s largely played key role in regulating the rule of demand and supply by providing subsidies in certain sectors with the sole aim of controlling unrestricted market activity. The state's huge investment on various sectors of public welfare such as transportation, education, health, agriculture and even on industrial productions during 1950s to 1980s provides sufficient logic to legitimise the argument. The state had played a remarkable role in bringing society, culture and economy together. This does not mean that the economy was in pre-market mode of production and conventional mode of reciprocity and redistribution had ruled the market relation but the point is that the market had not also achieved the status of 
Polanyi's self-regulating market.

As far as the post 1980 Nepalese market is concerned, though it seems sufficiently free there are various "invisible hands" besides money that determine the decisionmaking in modern economy. Referring to Kenneth Arrow, Karnik (2008) asserts that mere forces of demand and supply are not adequate for markets to function; "social norms [also] play a crucial role in determining which markets come into existence and which do not" (p. 104).

The production and consumption patterns substantially vary depending upon the nature of the society and the culture in which a society is organised even if the countries adopt same self-regulated market mechanism. The production and consumption pattern observed in Nepalese society does not necessarily correlate with that of American and European societies regardless of free market economy in all these settings. Harriss (2002) has also made observation by analysing the different patterns of growth rate achieved by the north and south Indian states under the same rubric of economic liberalisation adopted since 1990s. The development of new forms of institutionalism either in the form of protective policies, domestic production or as price regulating strategies in developing countries makes difficult to imagine the existence of perfect self regulating market. On the other hand, monopolistic and syndicate strategies of small group of traders/entrepreneurs in Nepal challenge the very functioning of market mechanism. In such situation, money loses its strength to regulate pricing and market transaction.

Contrary to Polanyis proposition, market and non-market exchange need not to be taken antithetical because various scholars argue that reciprocity and redistribution can co-exist with market allocation. Only the possible is market exchange dominate in some societies and in others vice versa. So Polanyi's way of dealing with these two types of exchange exclusive of each other needs to be reworked. New Institutional Economists (NIE) such as Douglass North claim that reciprocity and redistribution may have a useful role to play even in modern societies as an alternative to market transactions (Karnik, 2008). Polanyi's conceptualization of bifurcation of market and non-market mode of exchange becomes further complicated when economy of developing countries like Nepal is brought under this. That is, smooth functioning of self-regulating market even in Nepal is difficult to imagine; rather the institutional frameworks are held responsible in shaping market transaction either leading to inefficiency or making society more unproductive, as argued by North (Harriss, Hunter and Lewis, 1995). Nepal's lowest economic growth rate is an instance of how culturally and politically shaped institutional frameworks are not being able to achieve satisfactory growth irrespective of official recognition of free market since last three decades (since 1980s).

\section{NEPAL'S EXPERIENCE OF FREE MARKET}

Though weakening of the state centred approach has been realised as early as since 1980s, the collapse of the Soviet Union and the end of the cold war in 1990s further geared up the need of market centred approach (Karnik, 2008). With the introduction of Structural Adjustment Policies (SAPs) by IMF and the World Bank in 1980s the third world countries were pressurised to revise their economic policies making compatible with the principles of free market. On the one hand these institutions professed belief in the free market system, and intervened in exchange rate 


\section{Crossing the Border: International Journal of Interdisciplinary Studies}

markets introducing various measures. Amid these inconsistencies they compelled the third world governments to remove the state intervention on market for its free and fair functioning.

Nepal had been remained historically self-sufficient and the idea of foreign was substantially new because of their isolation from international affairs till 1950s (Bista, 1991). As it opened for international community in 1950s it started to receive considerable amount of foreign aid, which now consists of significant share in its total annual budget. State regulated economic model of the Panchayat government until 1990s only partially allowed the private investment in limited sectors; and the price was regulated to the large extent by the parallel state investment in most of the sectors such as service and production. The state run brick, leather and cigarette industries are few of the instances; but as the IMF and the World Bank intervened on the market with structural adjustment policies, Nepal wholeheartedly welcomed the economic liberalisation policies. Nepalese economy since 1990s appeared to be a self-regulating and independent in the national level. Since then the state has been seen almost absent from the market. But, is it self-regulating and independent in real sense in accordance with the Polanyian framework of dis-embeddedness while foreign aid dependency and WTO regulations are already there?

Polanyis claim is that historical transition from an embedded to dis-embedded economy did not reflect a natural, evolutionary process inherent to the logic of markets, which goes beyond the belief of the neoclassical economists of his day. For instance, Hayek (1944) argued that the self-regulating market mechanism was rather produced by concrete state interventions and political practices. He clearly illustrates, "Laissez-faire was planned ..." (Hayek, 1944, p. 141). Polanyis observation that the origin of market economy was a sudden eruption rather than planned and having gradual development (Hart and Hann, 2009) could not be easily verified if one looks at the historical development of free markets in developing countries. Nepal's entry to the laissez-faire economy was neither through natural evolutionary process nor was an abrupt shift, but was consciously designed efforts of international financial institutions imposed from the top to comply with Washington Consensus. Protectionist policies that Nepal adopted till then in the guise of an import substitution strategy resulted in inefficiency and the unproductive use of resources pushing to adopt structural adjustment policies (Khanal, 2012). Though 1990s democratic change is marked as the beginning of economic liberalisation in Nepal, market friendly environment had been already created by imposing structural adjustment policies since the beginning of 1980s.

Aid-dependent economy of Nepal had no other alternatives but to submit to the international intervention otherwise it had to undergo severe challenges. The government was dependent on foreign aid not only for investment but also for administrative expenses (Panday, 1989, p. 316), which had market depend on the state; and state on the donor agencies. For instance, in the first three years of the seventh five year plan (1985-1990), foreign aid had shared 60\% of development expenditure, which included expenditures on salaries and other recurring items to a substantial degree (Panday, 1989, p. 316). So the goal of the SAP had been set to liberate market from the grip of the state and let it function independently under the very principles of self-regulating market. This effort resulted in reduced subsides in service sector and agriculture in particular leading to rapid escalation of price in Nepal's case. 
Nepal's shift to market centred approach principally strengthened the role of the free market but could not reduce the degree of aid-dependency. Only little was changed even after the restoration of the democracy in 1990s although economic liberalization has been made the guiding framework for economic development. As the degree of freedom that Nepal's market is always questioned, Polanyi's concept of "embeddedness" has become a matter of degree, not only of kind with regard to Nepal's move towards liberal economy.

According to Bista (1991), as the Nepali idea of aid is largely affected by the high caste fatalistic values and opinions of begging and charity, Nepal's foreign aid dependency goes back to its root on ruling class cultural values which is by nature fatalistic. He further asserts that the attitude to the foreign aid is greatly affected by the sense of paternal dependency. If we follow his arguments, we should believe that the foreign aid dependency is our cultural production that subsequently has determined the nature of our social and economic interaction. Karnik (2008) has also asserted that mere forces of demand and supply are not adequate for markets to function; "social norms [also] play a crucial role in determining which markets come into existence and which do not" (p. 104).

The production and consumption patterns substantially vary depending upon the nature of the society and the culture in which a society is organised even if the countries adopt same self-regulated market mechanism. The market pattern observed in Nepalese society does not necessarily correlate with that of American and European societies regardless of free market practices in all these settings because when global free market values encounter with local needs and values the first are reconfigured by incorporating the parts of the local values. Harriss (2002a) has also made inspiring observation on the role of local values by analysing the different patterns of growth rate achieved by the north and south Indian states under the same rubric of economic liberalisation adopted since 1990s. The reflection of local values either in the form of caste based occupation, kinship based trust, and paternal dependency in economic behaviour in developing countries makes difficult to imagine the existence of perfect self regulating and dis-embedded market.

Developing economies experience differential growth rate primarily due to the interplay between "self-regulating" market, social values (e.g. fatalism, paternalism) and the elements of social capital (e.g., trust, kinship). Domination of familial relation in large business enterprises, which is a common feature of developing economies, has been a challenge to Indian economy in the era of global economic competition (Harriss, 2002b). India has recently experienced the crisis in family business because of its declining market capitalism in contrast to multinational corporate business (Harriss, 2002b); but in Nepal's case large business enterprises are still under the control of few entrepreneur families from Newar and Marwari communities. On the other hand, monopolistic and syndicate strategies of small group of traders/ entrepreneurs in Nepal have been appeared as impediments for very functioning of market mechanism.

The problem with dis-embeddedness is that Polanyi neither comprehensively defined the concept nor made any analysis of the local variation in self-regulating market. Primarily drawing on from the experience of eighteenth century Britain, and from the consequences of Speenhamland law, he tried to develop a universal law of market and economy (Polanyi, 2001 [1944]). He realised the role of cultural and 


\section{Crossing the Border: International Journal of Interdisciplinary Studies}

social aspects in the evolution of economic systems. In his both economic systems (pre-market and market) the social and cultural aspects are there; but only the difference is that the way these aspects are dealt in these market systems. The centrality of money in regulating price and market relation in capitalist economy as forecasted by Polanyi did not leave the same impression in developing economies as compared to the advanced economy of the first world.

Fatalistic and paternalistic values can play influential role to determine the nature of trust in which market relations between entrepreneurs or between entrepreneurs and consumers are formed. The element of trust in Polanyis pre-market economy stems from mutuality and reciprocity but the same mutuality is taken as contingent variable having utility function in market economy (Gudeman, 2009). He further states that the ties of trust may play several roles in markets such as ensuring that the information provided between entrepreneurs is reliable. The same can be said about the relationship between entrepreneurs and consumers. On the other hand, the degree of trust is subject to the nature of kinship dynamics in which the economic system rests on. Harriss (2002b) following the idea of Arrow has stated the correlation between the lack of trust and economic backwardness. In these circumstances, economic activities require high transaction costs. So trust as an element of social capital gets the "self-regulating" market embedded with various aspects of culture just by instigating the interplay between market, social categories (caste, kinship), mutuality and information sharing.

\section{CONCLUDING REMARKS}

For Polanyi, it was the great transformation, not only the industrial revolution, which brought radical changes in the economic relationships chiefly in eighteenth century Britain and Europe. The shift from non-market mechanism of economic exchange rooted in the notion of redistribution and reciprocity to the self-regulating market mechanism solely controlled by the money itself was the great transformation. His non-market and market economy are exclusive of each other in which the latter commoditises non-market elements such as labour, land and money. Contrary to his proposition, coexistence of the notions of both markets in different parts of the world have been reported by various scholars on the one hand; and adaptive strategies of the market economy with social and cultural dynamics for its long run existence has put the notion of dis-embeddedness at stake in the context of developing countries' market practice on the other.

As far as Nepal's market exercise is concerned, with a long history of money based exchange, it has experienced various forms of economies. Pre-1980s was largely marked by controlled market under state led development approach; post1980s by withering away state control; and by full-fledged economic liberalisation since 1990s. So, the changes in the mode of economic exchange are partly spontaneous and partly planned but not sudden and abrupt as Polanyi observed in his case. Because of the fatalistic values in ruling position Nepal's market activities have been appeared synonymous with foreign aid, chākari (sycophancy) and āfno mānchhe (nepotism), paternalism, trust shaped by kinship and caste based occupational norms, and monopolistic mentality. These elements have pushed the positive values that inspire culture of work and labour into the margin (for example, value system of ethnic groups according to Bista (1991), although the relevancy of this argument 
could also be brought into the debate).

The culture of fatalism has, thus, though not fully, penetrated into both economic and non-economic interactions of Nepalese social life. That is, causal relationship between the ruling values and the notion of trust has to be given due recognition to understand the degree of embeddedness of Nepal's economy into culturally shaped institutions despite Nepal's hard effort to comply with the self-regulating market principles. The institutions, either culturally based or corporate, are always there with the market squeezing its smooth and free functioning through several monopolistic strategies. The politics of trust and power dynamics in societies like Nepal, which Polanyi ignored in his analysis of self-regulating market, have turned to be key factors of market manipulation. So, Nepal's market seems more regulated by non-market and non-monetary elements such as power, politics, and intermediate institutions instead of regulating itself.

\section{REFERENCES}

Bista, D. B. (1991). Fatalism and development: Nepal's struggle for modernization. Patna: Orient Longman Ltd.

Fusfeld, D. R. (1988). The economic thought of Karl Polanyi. Journal of Economic Issues, 22(1), 264-268.

Gudeman, S. (2009). Necessity or contingency. In C. Hann, \& K. Hart, Market and Society: The Great Transformations Today (pp. 17-37). Cambridge: Cambridge University Press.

Hann, C., \& Hart, K. (2009). Introduction: Learning from Polanyi 1. In C. Hann, \& K. Hart, Market and Society: The Great Trasformation Today (pp. 1-16). Cambridge: Cambridge University Press.

Harriss, J. (2002a). Institutions, politics and culture: A case for 'Old' institutionalism in the study of historical change. London: Development Studies Insttitute.

Harriss, J. (2002b). On trust, and trust in Indian business: Ethnographic explorations. London: Development Studies Institute.

Harriss, J., Hunter, J., \& Lewis, C. M. (1995). Introduction: Development and significance of NIE. In J. Harriss, J. Hunter, \& C. M. Lewis, The New Institutional Economics and Thirld World Development (pp. 1-16). London: Routledge.

Hart, K. (2009). Money in the making of world society. In C. Hann, \& H. Keith, Market and Society: The Great Transformation Today (pp. 91-105). Cambridge: Cambridge University Press.

Hayek, F. V. (1944). The Road to sefrdom . London: George Routledge and Sons.

Issac, B. L. (2005). Karl Polanyi. In J. G. Carrier, A Handbook of Economic Anthropology (pp. 14-25). Cheltenham: Edward Elgar Publishing Limited.

Karnik, A. (2008). Transformations, then and now: The appeal of Karl Polanyi. Economic and Political Weekly, 43(48), 101-109.

Khanal, D. R. (2012). Trade liberalization, poverty and development in Nepal. South Asian Journal (35), 79-94.

Maertens, E. (2008). Polanyi's double movement: A critical reappraisal. Social Thought and Research, 29, 129-153.

Panday, D. R. (1989). Administrative development in a semi-dependency: the experience of Nepal. Public Administration and Development, 9, 315-329. 


\section{Crossing the Border: International Journal of Interdisciplinary Studies}

Polanyi, K. (2001 [1944]). The great transformation: The political and economic origins of our time. Boston: Beacon Press.

Shrestha, D. B., \& Singh, C. B. (1972). The history of ancient and medieval Nepal. Kathmandu: D. B. Shrestha and C. B. Singh.

Stigliz, J. E. (2001 [1944]). Foreword. In K. Polanyi, The great transformation: The political and economic origins of our time (pp. VII-XVII). Boston: Beacon Press.

\section{ABOUT THE AUTHOR}

Krishna P. Pandey teaches sociology at Purbanchal University in Biratnagar, Nepal since 2004 and currently doing Ph.D. in Sociology from South Asian University in New Delhi, India. His Ph.D. research is on ethnic identity and everyday life of Madheshis and non-Madheshis of eastern Tarai. His research interests are on topics related to social studies such as indigenous economy, ethnic identity, everyday life, social interaction, and minority studies. Email: krishnapandey40@yahoo.com 